\title{
Relationship of Microalbuminuria Levels among Patients with Type 2 Diabetes and its Complications in Western Uttar Pradesh
}

\author{
Abhishek', Shivangi Gupta ${ }^{2}$, Anil Kumar Kem ${ }^{3}$ \\ ${ }^{1}$ Post Graduate 3rd year, Department of General Medicine, Saraswathi Institute of Medical Sciences Hapur (U.P.), ${ }^{2}$ Post Graduate 2nd year, Department of General \\ Medicine, Saraswathi Institute of Medical Sciences Hapur (U.P.), ${ }^{3}$ Professor and HOD, Department of General Medicine, Saraswathi Institute of Medical Sciences \\ Hapur (U.P.)
}

\section{Abstract}

Background: To study the relation of levels of microalbuminuria among patients with type 2 diabetes and its complication in western UP. Subjects and Methods: The study included 110 patients with Type 2 diabetes mellitus visiting the diabetic clinic. Patients with complications, such as retinopathy and neuropathy were diagnosed on the basis of history, clinical examination and investigations. Microalbuminuria levels were compared in patients with complications (subjects) of Type 2 diabetes mellitus and patients without complications (control). Results: The study revealed that microalbumin levels in the urine are at significantly higher range in patients with complications $(\mathrm{p}<0.05)$ mainly with diabetic retinopathy, as compared to patients with other complications. Conclusion: The study supports that microalbuminuria is significant among patients with diabetic complications and strict glycemic control can prevent microalbuminuria and thereby prevent progress on to diabetic nephropathy in patients with Type 2 diabetes mellitus.

Keywords: Microalbuminuria, Diabetes mellitus, Diabetic Retinopathy, Diabetic Neuropathy.

Corresponding Author: Dr. Abhishek, Post Graduate 3rd Year, Department of General Medicine, Saraswathi Institute of Medical Sciences, Hapur (U.P).

Received: August 2019

Accepted: August 2019

\section{Introduction}

Diabetes Mellitus refers to group of common metabolic disorders that share phenotype of hyperglycemia. Diabetes mellitus (DM) is the most common metabolic disorder characterized by chronic hyperglycemia and disturbances of carbohydrate, fat, and protein metabolism due to absolute or relative deficiency of insulin secretion or action. ${ }^{[1]}$ Diabetes Mellitus is increasing globally particularly in developing countries. More than $80 \%$ of diabetic death occurs in low and middle income countries. ${ }^{[2]}$ WHO projects that diabetes will be 7 th leading cause of death by $2030{ }^{[3]}$ There is an emerging epidemic of diabetes in India with more than 62 million diabetics with diagnosed disease. ${ }^{[4,5]}$

People with diabetes are at increased risk of chronic complications which affect many organ systems and are responsible for the majority of morbidity associated with the disease. The risk of chronic complications increases with the duration of hyperglycemia. Chronic complication includes vascular complications microvascular (retinopathy, neuropathy, and nephropathy) macrovascular (coronary artery disease and cerebral vascular disease)

Through our study, we tried to evaluate urinary microalbumin levels among various complications of type 2 DM and to assess the risk of nephropathy in patients with various diabetes complications.

\section{Subjects and Methods}

After approval from the ethical comittee, this study was conducted between August 2018 and January 2019. A total 110 patients were included 90 patients diagnosed with Type 2 diabetes mellitus and associated complications as subjects and 20 patients with Type 2 diabetes mellitus as a control. Patients with microvascular and macrovascular complication such as neuropathy, retinopathy and hypertention were diagnosed based on history, examination and investigations.

Microalbuminuria levels were compared between two groups, one with the complication (subjects) and other without (controls). Plasma glucose was measured in auto analyzer OLYMPUS AU 400 based on enzymatic method, fasting lipid profile - total cholesterol, triglyceride, HDL, LDL, VLDL and HbA1c was estimated using commercially available kit on the same day of collection.

\section{Statistical Analysis}

Data was collected and analyzed using SPSS software. The statistical significance was analyzed in the subjects and controls using the paired Student's t-test. Significance was considered for all tests $(\mathrm{p}<0.05)$

\section{Results}


In our study, we tried to evaluate the levels of urine microalbumin in diabetics with complications and in considered as controls. Total 110 patients enrolled in the study, 64 male and 46 female. 90 patients had complications (cases) and 20 were without complications (control).

The study revealed that level of microalbuminuria are at significantly higher range in patients with diabetic retinopathy $(\mathrm{p}<0.05)$, when compared with other complication of type 2 diabetes mellitus.

The study showed that urine microalbumin level in diabetics with peripheral neuropathy was found to be $87.6 \pm 75.5$ compared to $17.6 \pm 12.2$ in controls $(\mathrm{p}<0.00)$.

In diabetics with hypertension urine microalbumin level was $54.6 \pm 23.4$ and in controls $17.6 \pm 12.2(\mathrm{p}<0.00)$.

In diabetics with retinopathy urine microalbumin levels was $120.5 \pm 85.9$ compared to $17.6 \pm 12.2$ in controls $(p<0.00)$.

It was also seen that the patients with diabetic retinopathy showed poor glycemic control with HbA1C levels being highest in them, HbA1c being $11.5 \pm 2.3$ whereas controls had good glycemic control with HbA1c being 5.6 \pm 0.7 $(\mathrm{p}<0.00)]$

\begin{tabular}{|l|l|l|}
\hline Patient with type 2 DM & Urinary Microalbumin & P-value \\
\hline Neuropathy & $87.6 \pm 78.5$ & $\mathrm{P}<0.00$ \\
\hline HTN & $54.6 \pm 23.4$ & $\mathrm{P}<0.00$ \\
\hline Diabetic Retinopathy & $120.5 \pm 85.9$ & $\mathrm{P}<0.00$ \\
\hline DM without complications & $16.6 \pm 13.7$ & $\mathrm{P}<0.00$
\end{tabular}

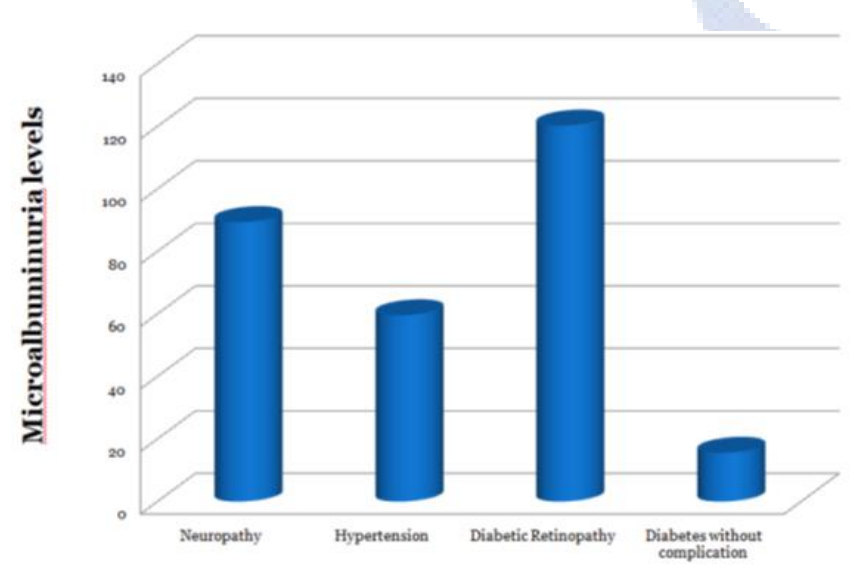

Patients with type 2 Diabetes Mellitus

\section{Discussion}

Diabetes-associated CHD risk, related in part to insulin resistance, may develop before hyperglycemia is established. Microvascular complications are diabetesspecific, whereas macrovascular complications have pathophysiologic features that are both shared with the general population and diabetes specific.

Chronic complication includes vascular complications microvascular (retinopathy, neuropathy, and nephropathy) macrovascular (coronary artery disease and cerebral vascular disease). ${ }^{[6]}$ Diabetic retinopathy (DR) is one of the leading causes of blindness in the world7. In a clinicalbased study, the overall prevalence of DR was $33.4 \%$ in
Type 2 diabetic patients8.

A link between renal and retinal angiopathy in diabetes has been long recognized, an effect that may be mediated through an increases in blood pressure fibrinogen levels, and lipoproteins. ${ }^{[9]}$ Diabetic neuropathy is a heterogeneous disease affecting different parts of the nervous system that present with diverse clinical manifestations. The involvement may be focal or diffuse. Most common among the neuropathies are chronic sensorimotor distal symmetric polyneuropathy and the autonomic neuropathies. ${ }^{[10]}$

Insulin resistance and hyperglycemia combine to make hypertension more prevalent in Type 2 diabetic patients. Approximately $15 \%$ of hypertensive patients are diabetic and approximately $75 \%$ of Type 2 diabetic patients are hypertensive. ${ }^{[11]}$ When urinary albumin excretion is $30-300$ $\mathrm{mg} / 24 \mathrm{hrs}$ is known as microalbuminuria and referred to as having incipient nephropathy.

Florakowski et al. reported an association of microalbuminuria and neuropathy in the absence of retinopathy and suggested that this provides support for a microalbuminuria element in the pathogenesis of diabetic neuropathy. ${ }^{[12]}$

Parving et al. also reported increased prevalence of peripheral neuropathy in patients with microalbuminuria and non-insulin dependent diabetes mellitus. ${ }^{[13]}$

Young et al. reported an association between the advancement of motor, sensory, and autonomic neuropathy that was independent of glycemic control. ${ }^{[14]}$

$\mathrm{HbAlc}$ could be used as objective measure of long term glycemic control. It establishes validated relationship between $\mathrm{HbA} 1 \mathrm{c}$ and average glucose across populations.

Diabetic nephropathy is the leading cause of chronic kidney disease (CKD), ESRD, and CKD requiring renal replacement therapy. We tried to evaluate the level of urinary microalbumin among various cases of type 2 diabetes mellitus with complications and to know the risk of nephropathy in patients with various diabetes complications and to find out whether there is any association between duration of diabetes, glycemic control and levels of urinary microalbumin.

\section{Conclusion}

The study supported the significance of microalbuminuria in patient with diabetic complication, strict glycemia control can prevent microalbuminuria and progression of diabetic nephropathy.

The presence of microalbuminuria is a powerful predictor of renal and cardiovascular risk in patients with Type 2 diabetes mellitus. Patients with Type 2 diabetes mellitus and associated complications such as retinopathy, neuropathy, and hypertension are at risk of developing diabetic nephropathy. Since Type 2 diabetes mellitus is slow onset disease and most of the Type 2 patients are unaware of the symptoms of diabetes mainly in rural population. Therefore, Screening for microalbuminuria is important for early detection and prevention of diabetic nephropathy. 


\section{References}

1. Prasad KD, Rajaseker P. Study of microalbuminuria as a cardiovascular risk factor in type diabetes mellitus. Iran J Kidney Dis 2012;3(1):12-6.

2. World Health Organization. Global Health Estimates: Deaths by Cause, Age, Sex and Country, 2000-2012. Geneva, WHO, 2014.

3. Mathers CD, Loncar D. Projections of global mortality and burden of disease from 2002 to 2030. PLoS Med, 2006, 3(11):e442.

4. Joshi SR, Parikh RM. India - diabetes capital of the world: now heading towards hypertension. J Assoc Physicians India. 2007;55:323-4.

5. Kumar A, Goel MK, Jain RB, Khanna P, Chaudhary V. India towards diabetes control: Key issues.Australia Med J. 2013;6(10):524-31.

6. Powers AC. Diabetes mellitus. In: Kasper DL, Braunwald E, Fauci AS, Hauser SL, Longo DL, Jameson JL, editors. Harrison's Principles of Internal Medicine. 16th ed. USA: The McGraw Hill Companies Inc.; 2005. p. 2152-80.

7. Taylor R. Practical community screening for diabetic retinopathy using the mobile retinal camera: Report of a 12 centre study. British diabetic association mobile retinal screening group. Diabet Med 1996;13(11):94652.

8. Rema M, Ponnaiya M, Mohan V. Prevalence of retinopathy in non-insulin dependent diabetes mellitus at a diabetes centre in southern India. Diabetes Res Clin Pract 1996;34(4):29-36.
9. Root HF, Pote WH Jr, Frehner H. Triopathy of diabetes; sequence of neuropathy, retinopathy, and nephropathy in one hundred fifty-five patients. AMA Arch Intern Med 1954;94(6):931-41.

10. Boulton AJ, Vinik AI, Arezzo JC, Bril V, Feldman EL, Freeman R, et al. Diabetic neuropathies: A statement by the American Diabetes Association. Diabetes Care 2005;28(4):956-62.

11. Sever PS, Poulter NR, Dahlof B, Wedel H, Beevers G, Caulfield M, et al. The Anglo-Scandinavian cardiac outcomes trial lipid lowering arm: Extended observations 2 years after trial closure. Eur Heart J 2008;29(4):499-508.

12. Florkowski CM, Jennings PE, Rowe B, Lawson N, Nightingale S, Barnett AH. Micro albuminuria in diabetic subjects with chronic peripheral neuropathy. Diabetes Res Clin Pract 1988;5(1):45-8.

13. Parving HH, Hommel E, Mathiesen E, Skøtt P, Edsberg B, Bahnsen M, et al. Prevalence of micro albuminuria, arterial hypertension, retinopathy and neuropathy in patients with insulin dependent diabetes. Br Med J (Clin Res Ed) 1988;296(6616): 156-60.

14. Young RJ, Maclntyre CC, Martyn CN, Prescott RJ, Ewing DJ, Smith AF, et al. Progression subclinical polyneuropathy in young patients with - Type 1 (insulin-dependent) diabetes: Associations with glycemic control and microangiopathy (microvascular complications). Diabetologia 1969;29:156-61.

Copyright: (C) the author(s), 2019. It is an open-access article distributed under the terms of the Creative Commons Attribution License (CC BY 4.0), which permits authors to retain ownership of the copyright for their content, and allow anyone to download, reuse, reprint, modify, distribute and/or copy the content as long as the original authors and source are cited.

How to cite this article: Abhishek, Gupta S, Kem AK. Relationship of Microalbuminuria Levels among Patients with Type 2 Diabetes and its Complications in Western Uttar Pradesh. Asian J. Med. Res. 2019;8(3):ME27-ME29.

DOI: dx.doi.org/10.21276/ajmr.2019.8.3.ME9

Source of Support: Nil, Conflict of Interest: None declared. 